\title{
Results of Aortic Diaphragm Surgery in Senegal: About 20 Cases
}

\author{
Diop Momar Sokhna ${ }^{1,}$, , Ba Pape Salmane ${ }^{1}$, Diagne Papa Amath ${ }^{1}$, Sow Ndeye Fatou ${ }^{1}$, Thiam Ibou ${ }^{1}$, \\ Diatta Souleymane ${ }^{1}$, Gaye Magaye ${ }^{1}$, Leye Mohamed ${ }^{3}$, Sene Etienne Biram², Doumbia Modibo', \\ Dieng Pape Adama ${ }^{1}$, Ciss Amadou Gabriel ${ }^{1}$, Ndiaye Assane ${ }^{1}$, Ndiaye Mouhamadou ${ }^{1}$ \\ ${ }^{1}$ Department of Cardiovascular and Thoracic Surgery, Cheikh Anta Diop University, Dakar, Senegal \\ ${ }^{2}$ Department of Intensive Care and Anesthesia, Cheikh Anta Diop University, Dakar, Senegal \\ ${ }^{3}$ Department of Cardiology, Cheikh Anta Diop University, Dakar, Senegal
}

\section{Email address:}

momarsokhna08@yahoo.fr(D.M. Sokhna),mansalb@yahoo.fr(Ba P. Salmane), diagnepapaamathdiagne@gmail.com(D.P.Amath), zenefes@gmail.com(S.N.Fatou), soul.diatta@yahoo.fr(D.Souleymane),mgaye99@yahoo.fr(G. Magaye),

leyemouhamed@gmail.com(L.Mohamed),biramsene@hotmail.com(S.E.Biram),modibodoumbia25@yahoo.fr(D.Modibo), padiengsala@yahoo.fr(D.P.Adama),cissgaby@yahoo.fr(C.A.Gabriel), lazanat@yahoo.fr(N.Assane), mondiaye@orange.sn(N. Mouhamadou)

${ }^{*}$ Corresponding author

\section{To cite this article:}

Diop Momar Sokhna, Ba Pape Salmane, Diagne Papa Amath, Sow Ndeye Fatou, Thiam Ibou, Diatta Souleymane, Gaye Magaye, Leye Mohamed, Sene Etienne Biram, Doumbia Modibo, Dieng Pape Adama, Ciss Amadou Gabriel, Ndiaye Assane, Ndiaye Mouhamadou. Results of Aortic Diaphragm Surgery in Senegal: About 20 Cases. Cardiology and Cardiovascular Research. Vol. 2, No. 2, 2018 , pp. 19-22. doi: 10.11648/j.ccr.20180202.11

Received: March 27, 2018; Accepted: May 14, 2018; Published: May 30, 2018

\begin{abstract}
Introduction: The subaortic diaphragm is a semilunar or circular membrane that is inserted into both the septal wall of the left ventricle and the base or adjacent part of the ventricular surface of the large mitral valve. It represents for 8$20 \%$ of all obstacles to left ventricular ejection. Material And Methods: This is a retrospective and descriptive study of patients with aortic stenosis under aortic diaphragmatic surgery operated over an 11-year period (January 2004-December 2015). Our study included 20 patients, 13 of which were male. The sex ratio was 1.85 . The average age of patients was 16.6 years [4-51 years]. Stage 2 dyspnea (NYHA) was the primary reason for consultation (17 patients). The heartbeat was regular sinus rhythm in 17 patients. Transthoracic echocardiography (TTE) found left ventricular hypertrophy in 19 patients. The average transaortic gradient was $55.68 \mathrm{mmHg}$ [24 - $92.5 \mathrm{mmHg}$ ]. Aortic insufficiency (IA) was found in 14 patients. An associated congenital heart defect was found in 9 patients. The approach was vertical median sternotomy and transverse aortotomy. The diaphragm was circular in 12 patients and semicircular in 8 patients. The aortic valve was tricuspid in 18 patients and bicuspid in 2 patients. The mean duration of extracorporeal circulation (ECC) was 74.66 minutes [35-119mn] and the mean duration of aortic cross-clamping was 49.11 minutes [20-102mn]. Results: After surgery, disorders of rhythm and conduction were present in 6 patients. At transthoracic ultrasound, left ventricular dysfunction was noted in 3 patients. A tamponade occurred in 1 patient justifying emergency drainage. Two recurrences of subaortic diaphragm were noted, one of which was reoperated after 9 years with a resection of the membrane and a replacement of the aortic valve by a mechanical prosthesis. One death was recorded four days postoperatively. The average postoperative gradient was $21.46 \mathrm{mmhg}$. The average follow-up time was 38 months [5 months - 115 months].
\end{abstract}

Keywords: Subaortic Diaphragm, Surgery, Senegal

\section{Introduction}

The subaortic diaphragm is a semilunar or circular membrane that is inserted into both the septal wall of the left ventricle and the base or adjacent part of the ventricular surface of the large mitral valve [1]. It represents $8-20 \%$ of 
all obstacles to ejection of the left ventricle [2].

\section{Material and Methods}

This is a retrospective and descriptive study of patients with aortic stenosis with aortic diaphragmatic stenosis operated over an 11-year period (January 2004 and December 2015). Data analysis was performed with Epi Info7 software, SPSS, Stata, and the Excel spreadsheet. This study included 20 patient, 13 of which were male. The sex ratio was 1.85 . The average age of patients was 16.6 years [451 years]. Stage 2 dyspnea (NYHA) was the primary reason for consultation (17 patients). Two patients had episodes of syncope and one patient had exercise angina. Cardiac auscultation found a systolic murmur of aortic stenosis in all patients and a diastolic murmur in 5 of them. The chest X-ray showed cardiomegaly with a mean cardio-thoracic index of 0.58 [0.38-0.65]. The heartbeat was regular sinus rhythm in 17 patients. Transthoracic echocardiography (TTE) found left ventricular hypertrophy in 19 patients. The average transaortic gradient was $55.68 \mathrm{mmHg}[24-92.5 \mathrm{mmHg}$.
Figure 1 shows the grades of aortic insufficiency (IA). An associated malformation was found in 9 patients divided as follows: ventricular septal defect (VSD) in 4 patients; patent duct arteriosus (PDA) in 2 patients; coarctation of the aorta (CoA) in 1 patient; right ventricular outflow tract obstruction in 1 patient and pulmonary stenosis in 1 patient. The approach was vertical median sternotomy and transverse aortotomy. The diaphragm was circular in 12 patients and semicircular in 8 patients. The aortic valve was tricuspid in 18 patients and bicuspid in 2 patients. Cardioplegia was crystalloid in 16 patients and blood in 4 patients. The mean duration of extracorporeal circulation (ECC) was 74.66 minutes [35-119mn] and the mean duration of aortic crossclamping was 49.11 minutes [20-102mn]. Subaortic diaphragm was resected in all patients. This resection was associated with septal myectomy in 7 patients and aortic valve replacement in 2 patients with significant aortic insufficiency. The associated procedures were VSD closure in 3 patients, PDA ligation in 2 patients, and coarctation repair in 1 patient.

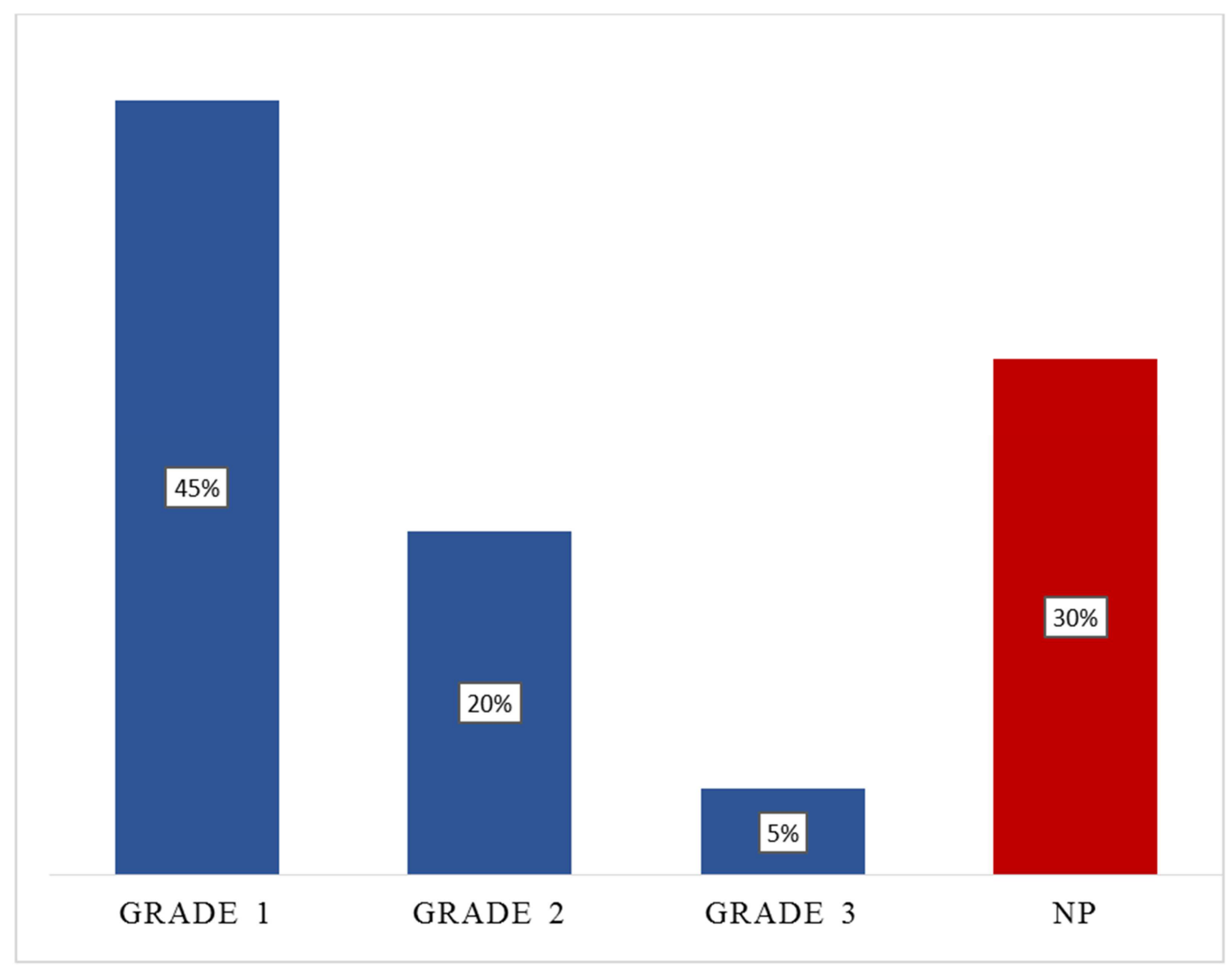

Figure 1. Distribution of patients according to the grade of aortic insufficiency preoperatively.

\section{Results}

After surgery, disturbances of rhythm and conduction were present in 6 patients as shown in Figure 2. At transthoracic ultrasound, LV dysfunction was noted in 3 patients. A tamponade occurred in 1 patient justifying emergency drainage. Two recurrences of subaortic diaphragm were noted, one of which was reoperated after 9 years with a resection of the membrane and a replacement of the aortic valve by a mechanical prosthesis. The low gradient $(17 \mathrm{~mm}$ $\mathrm{HG}$ ) of the second recurrence does not justify reoperation yet. One death was recorded four days postoperatively. The cause was heart failure refractory to treatment. The average postoperative gradient was $21.46 \mathrm{mmh}$. The average followup time was 38 months [5 months - 115 months]. 


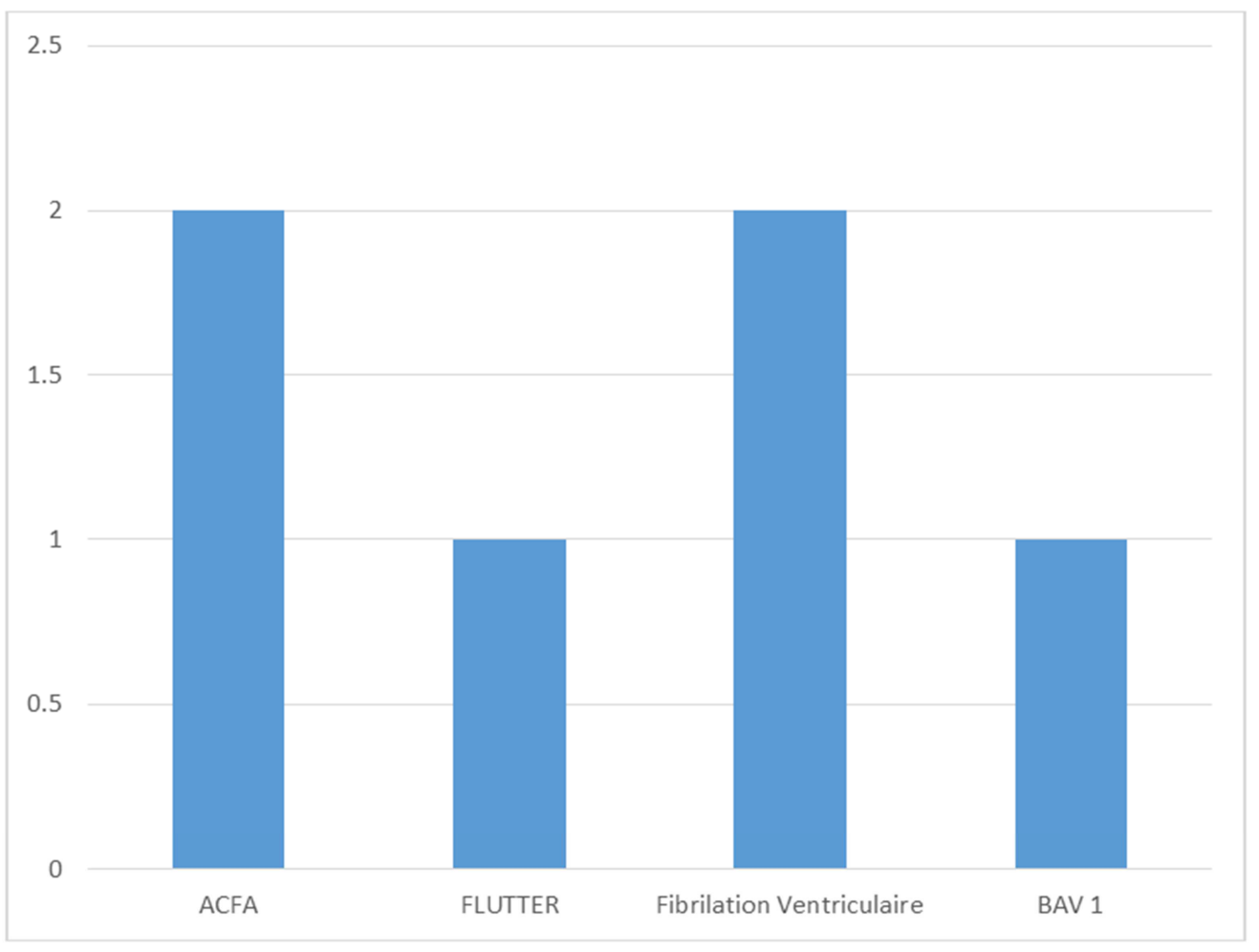

Figure 2. Disorders of rhythm and conduction after surgery.

\section{Discussion}

The average age of our patients is 16.6 years, which is higher than the average age in many series $[3,4,5]$. This could be explained by the delayed diagnosis and the delay between diagnosis and surgery. Dyspnea is the main reason for consultation. Transthoracic echocardiography allows the diagnosis and found aortic insufficiency associated 14 patients. Aortic insufficiency is found at a frequency ranging from $29.2 \%$ [4] to $79.5 \%$ [6]. According to most authors, the surgical indication is formal for the symptomatic subaortic diaphragm whereas in the absence of symptoms, the surgical attitude is variable and depends on several elements which the study allows to pose the operative indication. In this series the indication is based on the absence of symptoms on a gradient of at least $50 \mathrm{mmHg}$, the presence or worsening of the aortic insufficiency or the presence of an associated malformation requiring a cure under extracorporeal circulation [3, 4], but the debate persists as to the maximum gradient for the surgical indication [7-9]. In the Geva study, the indication for resection is based in $31 \%$ of cases for a peak gradient across the left ventricular outflow tract greater than $35 \mathrm{mmHg}$ and for $5 \%$ on a mean aortic insufficiency [10]. In the Drolet study, which included a cohort of 92 patients, half of the patients underwent surgery at an average of 2.2 years after diagnosis. He found that when surgery allows good resection of the left ventricular obstruction, the majority of operated patients $(82 \%)$ had either moderate or moderate aortic insufficiency at echocardiographic assessment at 3.7 years after surgery. The other half medically followed for moderate obstruction of the left ventricular outflow tract did not show progression of aortic insufficiency despite an average follow-up of 4.1 years. The incidence of progression of aortic insufficiency is 14 to $49 \%$ but remains moderate during the same period. This suggests that some patients could be safely monitored by echocardiographic controls [11]. The surgical strategy was resection of the subaortic membrane associated with septal myectomy in 7 patients. Indeed, according to several authors, the association with septal myectomy has considerably reduced both the immediate postoperative mean gradient and the rate of recurrence [12]. In contrast, other authors [3, 13] found no difference in postoperative mean gradient by the association or not of a myectomy. In the Hirata series [6], the group of patients with an isolated subaortic diaphragm had no significant differences in recurrence rates (23\% vs $30 \%)$ or re-interventions $(4.7 \%$ vs $4.4 \%)$ with or without a myectomy. The main complication of this myectomy is the presence of conduction disorders such as atrioventricular block. Parry [14] found that aggressive resection with extensive myectomy is accompanied by a $14 \%$ higher atrioventricular block rate. In the Drolet study, $6.12 \%$ of patients presented a complete atrioventricular block with pacemaker implantation [11]. One case of 1 st degree atrioventricular block is noted. Hospital mortality is low, especially for localized forms. In this series, it concerns 1 patient. In the literature it is estimated at $0-4 \%$, half of which occurs in the first 6 months [15]. Serraf [3] reported 2 cases of death with univariate statistical analysis a significant increase in the risk of premature death for NYHA class 3-4 
and advanced age at surgery while only NYHA class preoperative is an independent risk factor for multivariate analysis. Long-term mortality is also low [4, 6, 9, 13]. We report no late deaths after a follow-up period of about 3 years on average [5 months - 115 months]. In this series, two recurrences of subaortic stenosis were noted which one was reoperated 108 months (9 years) after the first intervention. In the Drolet study, $20.4 \%$ of patients were reoperated for recurrent subaortic stenosis [11]. The risk factors for subaortic stenosis recurrence on multivariable analysis were postoperative peak instantaneous left ventricular outflow tract Doppler gradient $>15 \mathrm{mmHg}$ and extension of the subaortic stenosis membrane onto the aortic valve. The risk factors for subaortic stenosis reoperation on multivariable analysis were age at initial surgery less than five years and extension of the subaortic stenosis membrane onto the aortic valve [5]. On the other hand, in Geva's study[10] in univariate analysis, younger age at first surgery, smaller aortic valve annulus diameter $z$ score, shorter distance between the subaortic obstruction and the aortic valve, and higher peak gradient across the obstruction on preoperative echocardiogram were significantly associated with subsequent reoperation. Additionally, peeling of the obstructive fibrous tissue from the aortic valve or mitral valve and myomectomy during the initial surgery were associated with future reoperation. The only postoperative echocardiographic variable associated with reoperation was higher peak gradient across the left ventricular outflow tract. In the multivariate analysis, independent predictors of earlier time to reoperation were distance between the obstructive lesion and the aortic valve $6 \mathrm{~mm}$ in systole and peak systolic gradient by Doppler $60 \mathrm{~mm} \mathrm{Hg}$. Some studies found age $<5$ years at subaortic stenosis repair to be an independent predictor of subaortic stenosis reoperation. As left ventricular outflow tract obstruction appears to gradually increase at rate of 1 to $3 \mathrm{mmHg}$ per year, it is logical that disease beginning at an earlier age would lead to increased risk of reoperation [16].

\section{Conclusion}

The subaortic diaphragm is relatively rare in our region; probably under diagnosed. The risk of sudden death remains present throughout the course of the disease. The etiology of aortic diaphragms remains unclear. It is linked to the combination of several risk factors including: hemodynamic turbulence in the left ventricular outflow chamber, genetic predisposition and mechanical stress. Surgery is highly codified with a tendency towards more and more aggressive techniques with respect to stenosis and myocardial component.

\section{References}

[1] Hassani. B. B. S, Tamdy. A, Rhissassi. J, Amri. R, Arherbi. M Le nouveau concept du diaphragme sous-aortique. Médecine du Maghreb 2010, 179:26-30
[2] Fettouhi. H, Amri. R, Tamdy A, Zarzour. J, Cherti. M. Subaortic stenosis with muscularization of the anterior mitral valve leaflet: two cases. Ann Cardiol Angeiol (Paris). 2010; 59:243-6

[3] Serraf A, Zoghby J, Lacour-Gayet F, Houel R, Belli E et al. Surgical treatment of subaortic stenosis: a seventeen-year experience. J Thorac Cardiovasc Surg. 1999; 117: 669-78

[4] Abid A, Denguir R, Chihaoui M, Khayati A, Abid F. Role of surgery in subaortic stenosis: report of 56 cases. Ann Cardiol Angeiol. 2001; 50:261-8.

[5] Julia S. Donald, Phillip S. Naimo, Yves d'Udekem, Malcolm Richardson, Andrew Bullock, Robert G. Weintraub, Christian P. Brizard, Igor E. Konstantinov. Outcomes of Subaortic Obstruction Resection in Children. Heart, Lung and Circulation (2017) 26, 179-186

[6] Hirata Y, Chen JM, Quaegebeur JM, Mosca RS. The role of enucleation with or without septal myectomy for discrete subaortic stenosis. J Thorac Cardiovasc Surg. 2009; 137:116872

[7] Coleman DM, Smallhorn JF, McCrindle BW, Williams WG, Freedom RM. Postoperative follow-up of fibromuscular subaortic stenosis. J Am Coll Cardiol. 1994; 24:1558-64

[8] Brauner R, Laks H, Drinkwater DC Jr, Shvarts O, Eghbali K et al. Benefits of early surgical repair in fixed subaortic stenosis. J Am Coll Cardiol. 1997; 30:1835-42

[9] Marasini M, Zannini L, Ussia GP, Pinto R, Moretti R et al. Discrete subaortic stenosis: incidence, morphology and surgical impact of associated subaortic anomalies. Ann Thorac Surg. 2003;75: 1763-8

[10] Alon Geva, Colin J. McMahon, Kimberlee Gauvreau, Laila Mohammed, Pedro J. del Nido, Tal Geva Risk factors for reoperation after repair of discrete subaortic stenosis in children. JACC Vol. 50, No. 15, 2007:1498-504

[11] Christian Drolet, Joaquim Miro, Jean-Marc Côté, John Finley, Letizia Gardin, Charles V. Rohlicek Longterm pediatric outcome of isolated discrete subaortic stenosis. Canadian Journal of Cardiology 27 (2011) 389.e19-389.e24 www.onlinecjc.ca

[12] Tefera E, Gedlu E, Bezabih A, Moges T, Centella T et al. Outcome in Children Operated for Membranous Subaortic Stenosis: Membrane Resection Plus Aggressive Septal Myectomy Versus Membrane Resection Alone. World J Pediatr Congenit Heart Surg. 2015; 6:424-8

[13] Dodge-Khatami A, Schmid M, Rousson V, Fasnacht M, Doell $\mathrm{C}$ et al. Risk factors for reoperation after relief of congenital subaortic stenosis. Eur J Cardiothorac Surg. 2008;33:885-9

[14] Parry AJ, Kovalchin JP, Suda K, McElhinney DB, Wudel J et al. Resection of subaortic stenosis; can a more aggressive approach be justified? Eur J Cardiothorac Surg. 1999; 15:6318

[15] Jones M, Barnhart GR, Morrow AG. Late results after operations for left ventricular outflow tract obstruction. Am J Cardiol. 1982; 50:569-79

[16] Foker JE. Outcomes and questions about discrete subaortic stenosis. Circulation 2013;127(14):1447-50 